\title{
NOVAS FORMAS DE ATUAÇÃO DO PROFISSIONAL DE SECRETARIADO EXECUTIVO
}

\section{THE EXECUTIVE SECRETARIAT NEW PROFESSIONAL PRACTICES}

\author{
Raul Vitor Oliveira Paes \\ Bacharel em Secretariado Executivo pela Universidade do Estado do Pará - UEPA \\ Secretário Executivo na Escola de Música, vinculada ao Instituto de Ciências da Arte, da \\ Universidade Federal do Pará - EMUFPA/ICA/UFPA \\ E-mail: rauloliverpaes@gmail.com (Brasil)
}

\section{Chussy Karlla de Souza Antunes}

Mestre em Gestão Pública pela Universidade federal do Pernambuco - UFPE Secretária Executiva da Escola Superior de Relações Públicas - ESURP E-mail: chussysa@ ccae.ufpb.br (Brasil)

\section{Cibelle da Silva Santiago}

Mestrado Profissionalizante em Gestão do Desenvolvimento Local Sustentável pela Universidade de Pernambuco - UFPE.

Secretária do Útil Comércio de Artigos de Armarinho Ltda.

E-mail: santiago.cibelle@gmail.com (Brasil)

\section{Mariane Ribeiro Zwierzikowski}

Bacharel em Secretariado Executivo pela Pontifícia Universidade Católica do Paraná - PUC/PR Administradora do Agenda Executiva E-mail: marianerz@live.com (Brasil) 


\title{
NOVAS FORMAS DE ATUAÇÃO DO PROFISSIONAL DE SECRETARIADO EXECUTIVO
}

\begin{abstract}
RESUMO
O presente artigo trata das novas formas de atuação do profissional de Secretariado Executivo no mercado de trabalho. Para mapear e compreender essas novas formas foi traçado um paralelo descritivo entre as características de cada nova área de atuação. Para isto foi adotada a pesquisa aplicada, sendo classificada como exploratória e descritiva, por meio de uma pesquisa bibliográfica, com tratamento feito pela análise de conteúdo. A partir disso, foram trabalhados cinco critérios para o mapeamento dessas novas formas de atuação: definição e esclarecimentos de cada atuação; perfil profissional requerido; expectativas do mercado e locais onde podem ser encontradas tais demandas. Para o atendimento das finalidades do trabalho, foram abordadas as seguintes formas de atuação: Assessoria - tanto em sua gênese bem como em formas atuais de exercício da função, como home office, escritórios virtuais e pool secretarial, consultoria secretarial e a área cooperativista. As conclusões apontam que tais áreas são pouco exploradas, mas já é possível perceber uma movimentação dos profissionais do secretariado iniciando suas atividades nessas áreas.
\end{abstract}

Palavras-chave: Secretariado Executivo; Atuação Profissional; Cooperativa.

\section{THE EXECUTIVE SECRETARIAT NEW PROFESSIONAL PRACTICES}

\begin{abstract}
This article deals with the executive secretariat new professional practices in the labor market. In order to map and understand these new practices, a descriptive parallel between the characteristics of each new professional practice was designed. In order to achieve this goal, applied research was adopted, classified as exploratory and descriptive, through a literature review, with treatment made by content analysis. Considering this scenario, five criteria were developed for the mapping of these new professional practices: definition and explanation of each operation; required professional profile; market expectations and where such demands can be found. In order to meet the work purposes, the following professional practices were addressed: Consultancy - both in its genesis and in current forms of exercise such as, Home Office, Virtual Offices, Pool Secretariat, Secretariat Consulting and the Cooperative area. The conclusions show that these areas are not explored to its fullest, but it is possible to perceive a movement of secretariat professionals starting their activities in these areas.
\end{abstract}

Keywords: Executive Secretary; Labor Market; Cooperative System.

Revista de Gestão e Secretariado - GeSec, São Paulo, v. 6, n. 1, p 99-125, jan./abr. 2015. 


\section{INTRODUÇÃO}

Desde a regulamentação do ensino superior para a profissão de secretariado pelo MEC, com a publicação da Lei $\mathrm{n}^{\circ} 7.377$, de 30 de setembro de 1985, a atuação do Secretário está fundamentada em sua formação acadêmica e em suas experiências cotidianas. Visando abordar as experiências profissionais, este trabalho foi elaborado a partir da percepção de novas formas de inserção/atuação mercadológicas existentes, assim como prospecções futuras da profissão secretarial. Nesse sentido, o tema desta pesquisa baseia-se em novas formas de atuação do secretário executivo e busca fornecer subsídios aos respectivos profissionais, orientando e esclarecendo essas novas oportunidades. Os objetivos deste trabalho são analisar o mercado de trabalho e as novas formas de inserção mercadológica para o profissional de secretariado; identificar as novas formas de atuação profissional: home office, escritórios virtuais, pool secretarial; explorar a área de consultoria secretarial, levantando os aspectos desta nova forma de inserção; e também, verificar de que forma o profissional de Secretariado pode atuar no ramo de cooperativas.

Contudo, esclarece-se que esta pesquisa é parte introdutória de uma pesquisa mais ampla, realizada pelos próprios autores em outro momento. Ela trata das novas tendências de inserção mercadológica que despontam no cenário secretarial colocando, particularmente, a proposta da construção de Cooperativas Secretariais, as quais deverão atuar juntamente à Assessoria e Consultoria, pois a Cooperativa pode ser uma forma mais econômica de prestar serviços e orientações no exercício da profissão.

Justifica-se o interesse dos autores em realizar tal estudo por tratar-se de um assunto inovador no mercado secretarial; é um nicho de mercado que ainda precisa ser explorado pelos secretários a fim de atender as demandas mercadológicas, bem como explanar sobre as demais formas de inserção profissionais em desenvolvimento no mercado para fornecer subsídios à atuação do profissional secretário executivo.

Revista de Gestão e Secretariado - GeSec, São Paulo, v. 6, n. 1, p 99-125, jan./abr. 2015. 


\title{
2 MERCADO DE TRABALHO E ATUAÇÃO SECRETARIAL
}

O mercado de trabalho está cada vez mais competitivo, a demanda por produtos e serviços tem aumentado significativamente. Dessa forma, a demanda por mão de obra qualificada está sendo mais exigida, a qual tem sido selecionada com muito rigor, em busca de profissionais mais completos, ou seja, que possuam diversas competências e habilidades capazes de acompanhar a evolução deste mercado.

Com o diploma ou outros atestados qualificatórios, o indivíduo era "empregável” aos cargos que correspondiam à formação socialmente oferecida pelo sistema educacional e, se necessário, executavam-se treinamentos curtos "on the job", numa época em que os níveis de acomodação eram elevados, o amplo mercado existente absorvia os que dispunham de qualificação e virtudes desejadas. (Paiva, 2002 apud Frigotto, 2002, pp.58-59)

\begin{abstract}
Um mercado é definido como um produto ou um grupo de produtos e uma área geográfica na qual ele é produzido ou vendido tal que uma hipotética firma maximizadora de lucros, não sujeita a regulação de preços, que seja o único produtor ou vendedor, presente ou futuro, daqueles produtos naquela área, poderia provavelmente impor pelo menos um pequeno, mas significativo e não transitório' aumento no preço, supondo que as condições de venda de todos os outros produtos se mantêm constantes. Um mercado relevante é um grupo de produtos e uma área geográfica que não excedem o necessário para satisfazer tal teste. (Possas, n. d., p.2)
\end{abstract}

Santos e Caimi (2009, p. 26) apontam o avanço do profissional e também o crescimento no mercado de trabalho, bem como afirmam que "no Brasil, o desenvolvimento da profissão acompanhou o ambiente empresarial. Na década de 1960, o trabalho do secretário passou a ser mais valorizado pelos empresários no contexto de treinamento gerencial". Com o passar dos anos, o secretário passou a se aprimorar como assessor e, consequentemente, a desempenhar outras funções, que a princípio, eram de responsabilidades dos executivos tais como: cogestão, consultoria e empreendedorismo. A atuação foi normatizada por meio da regulamentação da profissão pela Lei

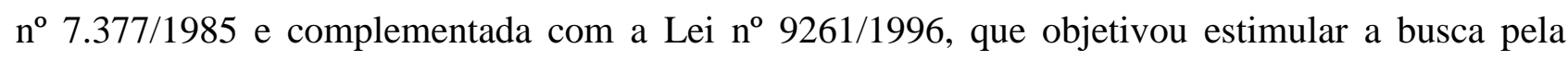
formação superior, uma vez que aqueles que possuíam formação no curso de bacharelado em Secretariado Executivo tinham mais oportunidades no mercado de trabalho.

O profissional de Secretariado Executivo já sente a necessidade de explorar este mercado de prestação de serviços. De acordo com Gomes (2007, p. 21) o "atual processo de globalização, nesta era da informação, acelerado pela internet, tornou os mercados extremamente acirrados, com competitividade extrema, priorizando a rapidez, a eficiência, a eficácia, a qualidade e o menor custo". Nesse mercado globalizado o profissional tem aderido às novas posturas profissionais, as

Revista de Gestão e Secretariado - GeSec, São Paulo, v. 6, n. 1, p 99-125, jan./abr. 2015. 
quais lhe possibilitam inovar seu comportamento no ambiente de trabalho, além de realizar ou monitorar atividades virtualmente.

No art. $4^{\circ}$ da Lei $n^{\circ} 7377$, de 30 de setembro de 1985, são citadas as atribuições do secretário executivo definidas em lei, onde o profissional estaria apto para atuar em diferentes instituições com naturezas e mercados dessemelhantes. Nesse contexto Medeiros e Hernandes (2012) citam algumas atitudes que precisam ser desenvolvidas: “É necessário que o profissional de secretariado tenha competência técnica e interpessoal, habilidades de liderança, relação com os clientes internos e externos à organização, seja líder que participa das tomadas de decisões; possua domínio de informática e seja responsável” (Medeiros \& Hernandes, 2012, p. 26).

Observa-se que, diante do crescimento do mercado de trabalho, o secretário também teve de evoluir em sua atuação profissional, deixando de ser um executor de atividades para delegar e gerenciar processos, informações e networking com seus stakeholders. Isso ratifica a evolução dessa demanda com uma pesquisa feita nos EUA, citada por Durante (2009, p. 29), a "profissão de secretário executivo é a terceira do mundo em número de profissionais". Acompanhando a crescente do mercado secretarial é essencial que o recém-formado e até mesmo o profissional que busca uma recolocação conheça quais são as novas áreas em que encontrará oportunidades. Para aprofundamento dos estudos sobre o assunto, segue-se a apresentação das novas áreas profissionais de atuação do secretário executivo, tanto as consolidadas (e suas respectivas inovações no modo de trabalho, como a área de Assessoria) como as recentes (em que o profissional pode atuar de forma inovadora, como as áreas de Consultoria e a Cooperativa).

\subsection{ASSESSORIA}

Uma função que é discutida constantemente na atuação do secretário executivo é a assessoria - é nela que o profissional apresenta sua atuação principal e encontra seu significado no âmbito organizacional ou grupal (Nonato Júnior, 2009). Sabino e Marchelli (2009, p. 621) pontuam que "a prática do secretário executivo configura-se como atividade de assessoria com vistas à realização de objetivos organizacionais". O conceito de assessoria, no campo gerencial, remete à assistência prestada a um executivo-chefe no desempenho de suas funções, facilitando o gestor em sua carga de trabalho (Albernaz, 2011), caracterizando dessa forma como atividade-meio na organização. Tal afirmativa é corroborada por Sabino e Marchelli, quando colocam que: 
o secretário executivo é essencialmente um assessor pessoal, que tem entre as suas atribuições a tarefa de organizar as rotinas de líderes atuantes nas empresas ou outras formas de organização, valendo-se fundamentalmente da ciência administrativa, que constitui o entorno conceitual básico para o desenvolvimento das tarefas que lhe são pertinentes. (Sabino \& Marchelli, 2009, p. 607).

Dessa forma, também se depreende que os conhecimentos necessários para a atuação na função de assessoria são provindas da área administrativa. A assessoria, na ciência da Administração, é classificada como uma relação de autoridade (em que também é conhecida como staff, em inglês), conforme apresentada por Hopp (1965), em que trabalha conjuntamente com as autoridades de linha.

As autoridades de linha são responsáveis pela decisão e execução dos assuntos principais da organização, em que a posição de comando e autoridade é sobre pessoas. Já as autoridades na área de assessoria são responsáveis por aconselhamentos e elaboração de sugestões, recomendações, facilitação de atividades, prestação de serviços especializados e exercício de controles (Hopp, 1965).

Dale e Urwick (1971), corroborados por Albernaz (2011) na área específica de Secretariado Executivo, apresentam as principais atividades possíveis de responsabilidade de um profissional de assessoria, em ordem de importância:

- trabalho de coordenação, reunindo as várias partes envolvidas, para desfazer malentendidos, bem como coletar e distribuir informações, atuando como secretários para comitês de coordenação;

- coleta, análise e explanação de políticas, planos e ações da alta administração;

- pesquisa econômica e de mercado, estudo de condições competitivas, bem como regulamentos, leis, decretos e resoluções governamentais;

- seleção das visitas e de solicitações para o executivo-chefe na alta administração.

De forma contemporânea, Décia (2005) identifica seis perfis de atuação do profissional de secretariado e, no último perfil, o profissional é visto como assessor organizacional, sendo atuante em organizações de médio e grande porte, de gestão de secretaria, que funciona como suporte às demais áreas e setores. A autora identifica o secretário executivo com autonomia e com responsabilidade de coordenação de pessoas, de processos (de recrutamento e seleção de pessoas) e de setores (logística e compras, por exemplo). Portanto, observa-se o desenvolvimento de atribuições da área de assessoria inerentes à atuação do profisssional de secretariado e a confirmação 
delas no trabalho organizacional.

Como a assessoria secretarial é prestadora de serviços especializados em sua área, então as tarefas para o assessoramento se valem dos fundamentos de planejamento, organização, direção e controle, para a melhor realização das atividades (Sabino, 2006); além de práticas de liderança, negociação e análise de situações para a solução de conflitos e mediação de relacionamentos. Assim, a assessoria secretarial se desenvolve como função-fim, a partir do momento em que o profissional de secretariado é caracterizado como gestor do seu setor (Durante, 2009).

É por isso que, nos últimos anos, uma forma inovadora de gestão está se desenvolvendo nas empresas que possuem cargos de secretariado em seus quadros funcionais, A Gestão Secretarial, que pode ser caracterizada pelo gerenciamento de informações, processos e métodos; bem como por liderança de pessoas e mediação de relacionamentos, de maneira coordenada ou imprevista, para o efetivo exercício da assessoria organizacional.

Interessante observar que o secretário executivo, enquanto gestor na Assessoria Secretarial, tem o seu perfil acrescido das habilidades e conhecimentos das funções de gestão (planejamento, organização, direção e controle), influenciando diretamente em três áreas de atuação: Gestão de Pessoas, Gestão de Processos e Resultados e Gestão da Informação; caracterizando, assim, as habilidades gerenciais como necessárias para a construção do profissional assessor (Castelo, 2007), percebendo, dessa forma, a exigência do mercado e da sociedade na atuação do profissional.

Conforme Sabino (2006), a natureza das atividades do ofício secretarial atesta a necessidade da profissão de secretário executivo em qualquer setor do mercado, sob qualquer porte organizacional. Tal afirmação pode ser constatada por Garcia (2000, p. 14), quando a autora diz que “a secretária está presente na indústria, no comércio, nas empresas prestadoras de serviços, nos órgãos gerenciadores, enfim, qualquer ramo de atividade humana".

Estudos recentes comprovam a necessidade do profissional de Secretariado como um assessor em vários segmentos mercadológicos, com destaque para a presença da figura masculina na função, o que mostra que não há distinção de gênero para o exercício da assessoria. Andrade Júnior e Sabino (2011), ao realizar uma pesquisa sobre a formação e empregabilidade do secretário executivo no estado de Sergipe, procuram saber a visão dos gestores sobre a profissão secretarial. Os resultados mostraram que o perfil do profissional está pautado na assessoria e na gestão de atividades e processos administrativos, sem haver distinção de gênero.

No tocante às necessidades do mercado de trabalho, Souza e Silva Filho (2010), ao 
analisarem o mercado para o profissional de secretariado na cidade de Cuiabá e arredores, no estado de Mato Grosso, concluíram que qualidades pessoais, habilidades de comunicação e expressão e conhecimentos em sistemas de informação estão entre os mais requeridos no mercado de trabalho naquela localidade, na função de assessoria. Com referência à função de assessoria, são elencadas três formas inovadoras de inserção mercadológica: o home office, os escritórios virtuais e o pool, como serão vistos na sequência.

\subsubsection{HOME OFFICE}

Para Schirigatti e Kasprzak (2007, p. 31) este é um novo conceito de trabalho "conhecido pela sigla SOHO, do inglês Small Office and Home Office ou Single Office/Home Office que, traduzido, significa escritório em casa, que pode desenvolver operações de pequeno e médio porte".

Mazulo e Liendo (2010, p. 21) quando afirmam que "há uma situação cada vez mais atual: a secretária que trabalha em sua própria casa (home office)" mostram uma nova tendência mercadológica, mas para que um profissional de secretariado possa atuar e assessorar seu gestor de sua própria casa é preciso que este tenha disponível uma infraestrutura de comunicação: computador, internet e telefone, ou seja, uma infraestrutura tecnológica e habilidade para seu uso. As autoras ainda afirmam que "na profissão de secretária, estamos dando os primeiros passos" quando se fala desse tipo de atendimento.

Segundo Capella e Almeida apud D’Elia, Amorim e Sita (2013, p. 411) o Home Office é exercido por trabalhadores independentes, apesar de algumas empresas adotarem o sistema de trabalho remoto quando os funcionários não precisam estar presencialmente no escritório. O trabalho secretarial em home office’s também depende da relação de confiança gestor-secretário. Porém, Pati (2012b) defende que os perfis profissionais que não combinam com o trabalho em home office são aqueles muito jovens ou recém-contratados, uma vez que precisam conhecer melhor as estruturas das empresas; os workaholics por trabalharem em excesso e terem grandes chances de confundir a estada em casa com trabalho; os acomodados ou indisciplinados e aqueles para quem a interação com o trabalho é fundamental.

A autora define que é fundamental conhecer o perfil de cada colaborador antes de atribuir a ele uma atividade que possa ser realizada em casa ou mesmo para um profissional que deseja abrir sua própria empresa. Pati (2012a) afirma que as áreas que mais contratam em sistema Home Office estão ligadas as áreas de vendas, tecnologia da informação, marketing e recursos humanos. 


\subsubsection{ESCRITÓRIOS VIRTUAIS}

Escritórios virtuais são modalidades de trabalho que oferecem ao profissional uma nova forma de atuação e que atrai pequenos empresários, oferecendo um local para que os trabalhos sejam desenvolvidos. De acordo com a reportagem apresentada no Jornal Paraná TV $2^{\text {a }}$ Edição, em 30 de julho de 2013, a estrutura de um escritório virtual pode ser compreendida também como uma grande cooperativa, onde pequenos empresários se reúnem e dividem espaço físico para acomodar suas pequenas empresas, dividindo as despesas operacionais do local.

Para Pereira e Büllau (2009) esses escritórios são considerados como um centro de negócios onde além de locar espaços, também se diferenciam ao propor ao cliente uma estrutura física e operacional pronta para o desenvolvimento de seu trabalho, oferecendo uma forma prática e econômica, com custo reduzido e sem burocracia. Para eles, este tipo de trabalho configura uma nova forma de prestação de serviços do profissional de secretariado, e pode contribuir também para o ensino da profissão dentro das academias à medida que abre novas possibilidades de inserção profissional. Os mesmos autores acrescentam que

o tema do ponto de vista dos profissionais da área secretarial, abrem-se duas linhas distintas de oportunidades. Uma primeira é de atuarem como profissionais ou gestores neste tipo de empreendimento, coordenando a execução dos serviços demandados pelos usuários. É uma nova forma de prestar serviços: ao invés de um único empregador, passa a ter um grupo de usuários dos serviços. Outra oportunidade é a implantação de empreendimentos similares. Nota-se que há demanda para este tipo de serviço e, portanto, tudo passa a ser uma questão de capacidade de investimento para viabilizar um empreendimento deste tipo. Naturalmente, a decisão de investir neste negócio exige um estudo prévio de viabilidade econômica e financeira. (Pereira \& Büllau, 2009, p. 229).

\subsubsection{POOL SECRETARIAL}

De acordo com o Dicionário online Michaelis (2013), pool, entre outros significados que a palavra pode adquirir, significa: "facilidades, serviços, para servir a um grupo". Mazulo e Liendo (2010, p. 21) afirmam que "há ainda alguns poucos casos em que a empresa adota uma central de suporte executivo ou pool de secretárias. Nesse caso, um número específico de secretárias assessora a todos os executivos da empresa, sem nenhuma exclusividade.” Nesse caso, o trabalho em pool representa um trabalho em grupo, em que o profissional submetido a esta nova forma de atuação necessita, primeiramente, de habilidades para trabalhar em equipe. 
Os profissionais que necessitam trabalhar em equipe também têm de ter habilidades para administrar conflitos, habilidades para comunicação, pró-atividade, saber inovar, e também saber desenvolver confiança no profissional que está ao lado (Administradores, 2013).

gestores precisam e querem colaboradores que se comuniquem, que construam ideias novas e que pensem juntos para o desenvolvimento da empresa. Se até pouco tempo atrás apenas os profissionais de nível hierárquico mais elevado podiam (e deviam) contribuir com a empresa nesse sentido, hoje o comprometimento coletivo é imprescindível, independente de cargos e funções, atribuindo assim a devida importância à convivência em grupo. (Tortorette, 2010, p.1).

Mazulo e Liendo completam a definição de pool expressando as respectivas opiniões:

Acreditamos, porém, que essa política de trabalho causa atritos e perde sua consistência quando nos deparamos com a possibilidade de a secretária auxiliar o executivo em assuntos pessoais (contas bancárias, suporte à família etc.), o que causa certo desconforto, uma vez o que o executivo tem sua vida pessoal aberta para várias pessoas (Mazulo \& Liendo, 2010, p. 21).

De acordo com Nasser (2008), poucos profissionais gostam desse tipo de trabalho uma vez que vários perfis de secretários são colocados lado a lado, assim como níveis de desenvolvimento e competências profissionais. A autora afirma que

infelizmente, num pool de secretárias com três ou mais secretárias, elas também têm de se preocupar com o trabalho das outras colegas. Em geral, as mais competentes sempre se destacam e, para o bom andamento do setor, terminam o trabalho da secretária mais lenta ou menos competente para executar determinada tarefa. [...] Pools de secretárias mal administrados só servem para criar intrigas, ciúmes, injustiças, competição e atritos entre elas, porque, cada uma sempre quer defender seu território e manter seus privilégios (marcar férias primeiro que as outras entrar mais tarde, sair mais cedo, decidir sozinha as atividades que devem fazer em grupo, ter direito a aumento ou promoções, cursar idiomas, delegar tarefas às outras, mas não colaborar etc.). (Nasser, 2008, p. 1).

\subsection{CONSULTORIA}

De acordo com o Instituto Brasileiro de Consultoria - IBCO, esse tipo de atuação tem sido fundamental diante dos desafios de gestão de empresas na atualidade, pois a atuação de especialistas constitui uma grande estratégia nas organizações, neste contexto é importante definir o que é um consultor. O presente artigo considera a definição de Block: "Consultor é a pessoa que tem certa influência sobre um indivíduo, um grupo ou uma organização, mas não tem poder direto para efetuar mudanças ou implementar programas e gerente é alguém que tem responsabilidade direta sobre a ação" (Block, 2013, p. 36).

Revista de Gestão e Secretariado - GeSec, São Paulo, v. 6, n. 1, p 99-125, jan./abr. 2015. 
$\mathrm{O}$ autor explica que quando o cliente procura um consultor, ele cria expectativas sobre o profissional e o serviço que será prestado, pois acredita que o consultor como conhecedor do problema, deverá oferecer a solução. Assim, é importante que o cliente entenda que a responsabilidade é igualmente dividida. E nesse sentido é válido entender estes dois tipos de consultoria:

1) Consultoria de recursos (conteúdo e prescritiva): O consultor fornece informações técnicas e serviços ou recomenda um programa de ação, transferindo conhecimento. Esse tipo de consultoria vem reduzindo seu uso com o passar do tempo. 2) Consultoria de Coaching (procedimentos de processo, assessoria): O consultor atua como um facilitador de mudanças, ajudando a organização a resolver os seus problemas e a escolher as modificações organizacionais e as técnicas apropriadas à mudança (Rodrigues, 2002, p.18).

Em ambos os aspectos a função do consultor é a mesma: aconselhar os contratados a tomar decisões estratégicas para a melhoria dos seus processos organizacionais, ou seja, toda ação de consultoria visa proporcionar algum tipo de mudança. Block (2013, p. 39) afirma que "toda vez que aconselhamos alguém que está na posição de fazer escolhas, estamos dando consultoria". Também afirma que, para fornecer consultoria é preciso ter um conhecimento sobre a questão levantada pelo cliente, é preciso primeiramente uma competência técnica, pois sem este conhecimento não há como realizar atividades de consultoria, e que também são necessárias habilidades interpessoais e habilidades específicas da área.

Nesse momento é importante traçar um paralelo com o profissional de secretariado que tem como base de sua atuação a atividade de prestar suporte ao executivo. Para Mazulo e Liendo (2010, p. 151) "é mais do que isso, é um suporte na condução das ações, e muitas vezes a ação propriamente dita". As autoras afirmam que são esperados resultados positivos do profissional de secretariado uma vez que este detém conhecimento técnico, possui domínio operacional de seus equipamentos e também habilidades pessoais e habilidades na coordenação de serviços e pessoas.

Para Durante e Santos (2010) o que as empresas esperam do secretário atual é "alguém que opina, questiona, sugere justamente pelo vasto conhecimento que possui dos sistemas e subsistemas, bem como pela visão abrangente dos processos, ficando implícita sua participação mais efetiva e sua autonomia em gerir seu trabalho". Já Mazulo \& Liendo (2010) afirmam ainda que cabe ao profissional de secretariado o conhecimento das técnicas do gestor mas também um perfil capaz de liderar, motivar e comunicar-se efetivamente, além de habilidades para negociação e criatividade. 
Conforme afirma Block (2013), para que o profissional se coloque no mercado como um consultor é necessário ter o domínio de três conjuntos de habilidades. Primeiramente são necessárias as habilidades técnicas, que se caracterizam pela formação de cada profissional configurando-se, então, como os aspectos específicos de cada disciplina; Para Consultorias Secretariais, as habilidades técnicas podem ser concebidas pela formação do profissional em Secretariado.

Em segundo lugar o autor elenca as habilidades interpessoais, que são definidas pela “capacidade de expressar ideias em palavras, ouvir, dar suporte, argumentar, basicamente para desenvolver uma relação pessoal” (Block, 2013, p. 40), que serão necessárias para uma consultoria efetiva.

Em terceiro lugar, o autor menciona as habilidades de consultoria, estas são elencadas de acordo com as fases da prestação do serviço. De acordo com o autor é possível compreender que as habilidades ligadas à consultoria envolvem muito mais do que conhecimento técnico, estão intimamente ligadas ao tato do profissional e a forma como este se comporta dentro do processo.

A necessidade de investir em algo que o trabalhador dominasse foi o fator crucial para o início das consultorias, pois esta era a possibilidade de o trabalhador continuar atuando na área em que esteve por anos e partilhar seus conhecimentos.

\subsection{COOPERATIVAS}

No Brasil o cooperativismo teve início legal em 1890 por meio de dois decretos que formalizavam a Cooperativa Militar do Brasil e a Cooperativa de Consumo Doméstico Agrícola. Cots (2007) faz um apanhado histórico e afirma que em 1934 o Decreto 24.647 dispunha sobre o cooperativismo sindicalista e serviu como abertura para outras cooperativas. Já em 1966 o Decretolei $\mathrm{n}^{\mathrm{o}}$ 59, baseado no Ato Inconstitucional 2, regulamentou a política nacional de cooperativismo, organizando o Conselho Nacional de Cooperativismo, que havia sido criado então pelo Decreto 46.438/59. Mas foi em 1971 que a Lei 5.764 de 16/12/1971 instituiu o regime jurídico das sociedades cooperativas que vigora até hoje.

O conceito de cooperativa manteve-se ao longo dos anos e é baseado na união de pessoas, trabalhadores ou profissionais. Eles se unem por iniciativa própria, em prol de congregar os interesses individuais e trabalharem juntos em busca de melhores condições de mercado.

De acordo com Crúzio (2005), as cooperativas diferem-se muito das empresas comuns por apresentarem características diferenciadas como, por exemplo, o livre ingresso, a variabilidade no

Revista de Gestão e Secretariado - GeSec, São Paulo, v. 6, n. 1, p 99-125, jan./abr. 2015. 
capital social por meio de quotas, possibilitar que o associado se desligue a qualquer momento desde que esteja em dia com suas obrigações, assegurar o direito do associado de votar nas reuniões e outros. $\mathrm{O}$ autor ainda apresenta garantias organizacionais da cooperativa, como: ter suas operações amparadas pelo Código Civil Brasileiro; desobrigar o trabalhador ou profissional associado a qualquer tipo de contribuição sindical, permitir que o associado contribua para a previdência social como pessoa física entre outros.

Segundo com Cots (2007) a história do cooperativismo registra uma cooperativa na cidade de Rochdale na Inglaterra que, em 1844, se utilizou de princípios para dirigir sua sociedade, São eles: $1^{\circ}$ ) adesão voluntária e livre; $2^{\circ}$ ) gestão democrática; $3^{\circ}$ ) participação econômica dos membros; $4^{\circ}$ ) autonomia e independência; $5^{\circ}$ ) educação, formação e informação; $6^{\circ}$ ) intercooperação; $7^{\circ}$ ) interesse pela comunidade.

Enquanto isso, a Lei ${ }^{\circ}$ 5.764/71 define a Política Nacional do Cooperativismo e institui o regime jurídico das sociedades cooperativas, os objetivos das cooperativas são definidos no artigo $5^{\circ}$ da referida Lei: As sociedades cooperativas poderão adotar por objeto qualquer gênero de serviço, operação ou atividade, assegurando-se lhes o direito exclusivo e exigindo-se lhes a obrigação do uso da expressão "cooperativa" em sua denominação. Esta lei permite aos sócioscooperados criarem uma cooperativa com o objetivo que lhes interessem, fazendo das Cooperativas uma forma de atuação no mercado atraente. Assim, profissionais com vontade de empreender podem se unir para viabilizar com maior facilidade seus respectivos projetos.

Iniciar tal atividade representa uma possibilidade real de inserção mercadológica para aqueles que desejam construir seu próprio negócio e estão dispostos a unirem-se com demais colegas de profissão em busca do fortalecimento no mercado e de melhores condições de atuação, como define o artigo $4^{\circ}$ da Lei 5.764/71: “Art. $4^{\circ}$ - As cooperativas são sociedades de pessoas, com forma e natureza jurídicas próprias, de natureza civil, não sujeitas à falência, constituídas para prestar serviços aos associados, distinguindo-se das demais sociedades”.

Para entendermos melhor o perfil profissional do cooperativista, e os propósitos destas pessoas que se unem, é preciso conhecer os propósitos da lei desta associação. O artigo 29 desta mesma lei trata dos associados e nos informa que o ingresso é livre a todos os que desejam utilizar os serviços prestados pela sociedade e partilhem dos propósitos sociais, desde que partilhem os propósitos sociais e preencham as condições estabelecidas no estatuto. Como a cooperativa é uma forma de associação, é imprescindível que os profissionais que desejam associar-se saibam trabalhar 
em equipe. Assim, além desses requisitos, para garantir o ingresso em uma cooperativa é fundamental que o profissional seja formado ou tenha profundo conhecimento na área da natureza da cooperativa.

\section{PROCEDIMENTOS METODOLÓGICOS}

Para fundamentar e sustentar este estudo, a pesquisa foi de natureza aplicada. Barros e Lehfeld (2000) afirmam que a pesquisa aplicada tem como motivação a necessidade de produzir conhecimento para aplicação de seus resultados com o objetivo de contribuir para fins práticos. Tendo uma abordagem qualitativa, pois tiveram como pretensão o entendimento da natureza de um fenômeno social, no caso as novas formas de atuação/inserção mercadológica para o secretário executivo.

Quanto aos objetivos, a pesquisa foi exploratória e descritiva. Segundo Gil (1999) a pesquisa exploratória é desenvolvida no sentido de proporcionar uma visão geral acerca de determinado fato. Normalmente esse tipo de pesquisa é usado quando o tema escolhido é pouco explorado. Por isso, tem-se como objetivo tornar mais explícitas as novas formas de atuação/inserção mercadológica para o secretário executivo na contemporaneidade. “A pesquisa exploratória não deve ser confundida com leitura exploratória, é realizada em área na qual há pouco conhecimento acumulado e sistematizado e a pesquisa descritiva expõe características de determinada população ou determinado fenômeno (Vergara, 2007, p. 47).”

Dados esses esclarecimentos, a pesquisa bibliográfica de acordo com Cervo e Bervian (2002) procura explorar o problema a partir das referências teóricas publicadas, e assim busca-se conhecer e analisar as contribuições culturais ou científicas existente sobre o tema. Por isso, ao final da pesquisa bibliográfica exploratória foram estabelecidos os critérios necessários a cada uma dessas formas levantadas em relação à definição e esclarecimentos sobre a nova forma de atuação, perfil profissional necessário, as expectativas do mercado, além de onde estas demandas mercadológicas podem ser encontradas, sem o compromisso de explicar os fenômenos descritos, embora sirvam no futuro de base para a explicação.

Foi realizado tratamento por meio da análise de conteúdo, a fim de identificar as características sobre o tema estudado. Em relação à definição de análise do conteúdo, Weber (1990, citado por Roesch, 1999, p. 170) afirma que este método "busca classificar palavras, frases, ou mesmo parágrafo sem categorias de conteúdos, utilizando desde técnicas simples até outras mais

Revista de Gestão e Secretariado - GeSec, São Paulo, v. 6, n. 1, p 99-125, jan./abr. 2015. 
complexas, que se apoiam em métodos estatísticos".

Portanto, faz-se necessário o aporte teórico que segue para que os objetivos sejam respondidos e a análise de conteúdo tenha o devido respaldo.

\section{APRESENTAÇÃO E ANÁLISE DOS RESULTADOS}

Diante do referencial teórico apresentado, apresenta-se a seguir a discussão e análise dos resultados referentes às novas formas de inserção do profissional de Secretariado no mercado, bem como possíveis consequências, implicações e perspectivas em cada uma das áreas.

\subsection{ASSESSORIA SECRETARIAL}

Uma definição interessante sob o ponto de vista específico para o Secretariado, é que uma das áreas de atuação do profissional é como assessor executivo, em que o secretário executivo é o agente executor e multiplicador mais próximo dos executivos das organizações (Bortolotto \& Willers, 2005).

Com base na revisão teórica, compreende-se que a assessoria pode ser definida como uma forma particular e inerente à atuação do profissional de Secretariado, na qual é caracterizada como uma assistência executiva, multiplicadora e adjunta aos órgãos decisórios (executivos, diretores, gerentes). Essa assessoria funciona como aconselhadora, orientadora e recomendadora de sugestões, planos e procedimentos, multiplicadora de processos e prestadora de serviços especializados na área de Secretariado, enquanto atividade-meio da organização.

Em razão dos estudos anteriores e da pesquisa bibliográfica realizada, a assessoria praticada pelo secretário executivo pode ser denominada de assessoria administrativa, assessoria secretarial ou assessoria executiva sem prejuízo das relações das nomenclaturas com a área secretarial. Para os fins deste trabalho, a nomenclatura assessoria secretarial é a mais adequada.

De forma resumida e sintetizada, apresentam-se as principais características do perfil do profissional de Secretariado na função de assessoria, com base em Castelo (2007) e Albernaz (2011): 
- habilidade de comunicação, no gerenciamento de informações e na administração de conflitos internos e externos;

- conhecimento da organização como um todo, tendo visão holística dela;

- planejamento e aplicação da liderança em equipes de trabalho;

- domínio e aplicação dos fundamentos da gestão organizacional, caracterizando-se como gestor em seu setor e servindo de suporte gerencial aos demais setores;

- ética e sensatez em seus pronunciamentos e ações;

- conhecimento da cultura organizacional, seus nichos mercadológicos e perfis de clientes.

Para que a Gestão Secretarial se consolide como parte da Assessoria Secretarial como função-fim, de forma a se configurar como uma nova forma de atuação do profissional de Secretariado no mercado de trabalho e na academia faz-se necessário ressaltar a necessidade de avançar em pesquisas teóricas e empíricas sobre o tema. Recentemente, foi apontado que os estudos sobre a temática têm cunho predominantemente teórico, "denotando estudos sem a comprovação de campo necessária para a construção do conhecimento na área.” (Silva, Barros \& Barbosa, 2012, p. 123).

Dessa forma, compreende-se que os conhecimentos e habilidades do profissional assessor versam sobre os conhecimentos técnicos, de relações humanas, de comunicação e em sistemas de informações, somados às qualidades pessoais são importantes para o exercício da função de assessoria, em que se mesclam o técnico e o relacional no trabalho secretarial. Atualmente, o secretário - além de assessor dentro da empresa em que atua - de uma única forma, pode exercer a assessoria na instituição de forma diferenciada, como o pool secretarial, bem como prestar assessoria externa, tendo como exemplos o home office e escritório virtual como formas de inserção mercadológica, conforme será visto a seguir.

\subsubsection{HOME OFFICE E O PROFISSIONAL DE SECRETARIADO}

O mercado atual está sendo modificado pela evolução das ferramentas tecnológicas e o trabalho em home office tem sido cada vez mais comum. Para a área secretarial ainda existem poucas pesquisas que referenciam o tema, mas já é possível sentir seus efeitos na medida em que um número cada vez maior de profissionais recebe de suas empresas aparelhos celulares que possibilitam o acesso à agenda dos gestores, e-mails, internet além da linha telefônica propriamente dita.

Revista de Gestão e Secretariado - GeSec, São Paulo, v. 6, n. 1, p 99-125, jan./abr. 2015. 
Para que o profissional possa atuar em casa, é preciso que este seja uma pessoa empreendedora, que aceita desafios e que está preparada para a assunção de riscos, que saiba gerenciar o tempo para a melhor disponibilidade dos trabalhos e que tenha inovação em seus serviços e práticas. A atuação via home office pode ser uma prática de um profissional ligado a uma empresa ou mesmo uma opção para profissionais que desejam investir em negócios próprios, como os consultores secretariais, secretários virtuais, entre outros.

Citam-se, então, alguns dos trabalhos que podem ser realizados pelos secretários nesta função home office, conforme a empresa O Secretariado Remoto (www.secretariadoremoto.com.br): atendimento telefônico; organização e manutenção de arquivos digitais; digitação, redação e revisão de documentos (correspondência, atas, mala direta, relatórios, propostas, apresentações, contratos, cartas, planilhas, tabelas, formulários, etiquetas etc.); logística de envio de presentes, brindes, flores e cartões; envio de convites e convocações, via e-mail ou correio; lembrete de compromissos e datas especiais (aniversários, viagens, consultas médicas); atualização e cancelamentos de serviços (telefone, TV a cabo, internet, concessionárias e outros); organização de documentos para envio à contabilidade; agendamento de reuniões; cotação e reservas de passagens, hotéis e restaurantes; controle de milhagens; seleção de fornecedores e serviços; cadastro e atualização de clientes; elaboração de apresentação em PowerPoint; pesquisa na internet; serviços em cartório, fórum e órgãos públicos; busca de nomes e endereços comerciais; assistência na organização de eventos, convites e convocações via $e$-mail; RSVP - ativo e passivo; elaboração e atualização de agenda telefônica; digitalização de documentos; elaboração de pesquisas de satisfação de clientes.

Um exemplo que pode ser usado para ilustração é a pesquisa de Barros, Vasconcelos, Silva, Brito e Silva Filho (2012), o qual estuda a atuação do secretário executivo virtual. Na pesquisa, os autores constataram que há demanda nos trabalhos do secretário executivo em home office, a partir de coleta de informações feitas por meio de questionários, por cinco secretários executivos que trabalham dessa forma no Brasil.

Os resultados do trabalho apontaram para a necessária divulgação da área de assessoria home office no Brasil, pois como é uma forma de trabalho inovadora no país há, ainda, certa desconfiança e incerteza dos clientes nos serviços prestados. Eles também apontam para o desenvolvimento e o crescimento dessa área de assessoria de acordo com esta nova forma de atuação. Por outro lado, já há clientes empresariais que contratam os serviços de assessoria virtual 
em atividades administrativas, financeiras, de recursos humanos e em projetos, pois existem algumas vantagens que corroboram para uma lucratividade econômica maior. As vantagens econômicas estão diretamente ligadas à redução do custo com aluguel/compra de espaço físico e sua manutenção, assim como transporte/traslado, alimentação e benefícios sociais do funcionário.

Dessa forma, pode-se afirmar que o home office possui grandes perspectivas de desenvolvimento, pois há profissionais de Secretariado que atuam no teletrabalho, porém é necessário que haja melhor divulgação e estudos mais aprofundados sobre o tema, para a consolidação dessa forma de inserção para a carreira do profissional de secretariado.

\subsubsection{ESCRITÓRIO VIRTUAL E O PROFISSIONAL DE SECRETARIADO}

Diante da pesquisa, é possível afirmar que profissionais de Secretariado que tenham perfil empreendedor e habilidades em comunicação e amplos conhecimentos em ferramentas tecnológicas para desenvolver atividades de modo eficiente e eficaz podem colocar-se neste mercado.

Pereira e Büllau (2009) citam o exemplo de duas secretárias executivas que se tornaram profissionais virtuais e abriram sua empresa (Empresa Libero - em São Paulo) executando serviços como controle de agendas, organizações de bancos, execução e envio de correspondências, inscrições em eventos, traduções e acompanhamento de visitantes. Mencionam, ainda, que, muitas vezes, um executivo não tem condições de manter um profissional de secretariado fixo, mas que ainda assim ele precisa de um serviço de assessoria.

Ainda assim é possível encontrar profissionais que atuam como Assistente Virtual, prestando serviços de secretariado a profissionais liberais, pessoas físicas e jurídicas. A revista Época publicou uma matéria intitulada “Assistentes Virtuais podem simplificar sua vida” em abril de 2013, o que mostra que é um caminho que está aberto ao profissional e cada vez mais utilizado por diversos profissionais de outras áreas.

\subsubsection{POOL SECRETARIAL}

O pool secretarial pode representar um desafio aos profissionais, acostumados até então a trabalhar sozinhos, a cuidar de maneira quase que exclusiva da agenda, compromissos e rotinas do gestor e/ou departamento que atua.

Nasser (2008) afirma que, com o intuito de cortar custos e aperfeiçoar as dinâmicas institucionais, a prática de pool tem sido uma tendência nas empresas, todavia representa "um

Revista de Gestão e Secretariado - GeSec, São Paulo, v. 6, n. 1, p 99-125, jan./abr. 2015. 
grande problema para as secretárias". Mas acredita que um pool bem administrado "só pode dar certo com regras bem definidas, imparcialidade e isento de qualquer privilégio a quem quer que seja, isto é, com direitos e deveres iguais a todas independente se a secretária atende a gerentes, diretores ou à presidência" (Nasser, 2008, p.1). Já Tortorette (2010, p. 1) ressalva que "dar o melhor de si é um dos comportamentos mais valorizados pelas organizações".

Conclui-se que o secretário necessita de maturidade profissional para trabalhar em um pool e neste contexto as pesquisas ainda são preliminares, uma vez que se configura como uma nova área de inserção mercadológica.

\subsection{CONSULTORIA SECRETARIAL}

Analisando o perfil profissional do secretário executivo, é possível afirmar que este desenvolve atividades de consultoria em suas atividades diárias, principalmente nas atividades em suporte ao executivo e gerentes que atende. De acordo com o novo perfil profissional vê-se que

as empresas esperam de [seus secretários] a consciência de seus deveres, dedicação ao trabalho, equilíbrio emocional para bem desempenharem suas tarefas, que sejam dignas de confiança, que saibam delegar tarefas quando necessário, que saibam resolver conflitos entre colegas de trabalho, que sejam capazes de trabalhar em grupo. À secretária cabe ainda conhecer as pessoas envolvidas no processo de produção, os gerentes, ter noção da divisão do trabalho estabelecido na empresa, reconhecer a autoridade competente (Medeiros \& Hernandes, 2012, p.283).

O perfil profissional de um consultor assemelha-se muito ao perfil profissional do secretário, e sua formação permite a atuação como consultor secretarial interno e externo. Para uma análise do mercado de consultorias é importante saber que as consultorias iniciaram na década de 1990, marcada pelo alto índice de desemprego.

O IBCO realizou uma pesquisa nos anos de 2011/2012 que teve por objetivo apurar e apresentar dados sobre as consultorias, dos quais nos interessam os resultados referentes ao perfil dos consultores, áreas de atuação e tendências de mercado. A pesquisa cita as seguintes áreas de atuação dos consultores - onde é possível que o Secretário Executivo desenvolva habilidades técnicas e consultivas para atuar - as quais são: gestão de recursos humanos e treinamento; melhoria de processos, qualidade e performance operacional; desenvolvimento organizacional e outras. Em uma pesquisa realizada na internet entre janeiro a julho de 2013, foi possível encontrar 
algumas consultorias secretariais que prestam serviços à sociedade, em sua maioria serviços ligados a gestão de documentos, realização de treinamentos e palestras, gestão de recursos e também relacionados à organização, sistemas e métodos. Podem ser citadas: Consultoria Secretarial Plano B, Great Start Serviços Ltda., Platinum Consultoria e Assessoria Secretarial, Plano Executivo e Secretária e Cia.

Esta pesquisa mostra que as consultorias secretariais têm grandes chances de estabelecer-se no mercado brasileiro, uma vez que o mercado está aberto aos novos setores. De acordo com o Financeiro (2012) "Os grandes eventos como a Copa do Mundo de 2014 e os Jogos Olímpicos de 2016 vão gerar excelentes oportunidades para fomentar o setor de consultoria no Brasil”.

\subsection{COOPERATIVA SECRETARIAL}

Um item facilitador no ingresso e desempenho de um secretário em uma cooperativa é que esse profissional tem conhecimentos e competências administrativas que viriam facilitar na gestão e oferta do serviço comum prestado pela organização (cooperativa), entretanto é importante observar sobre o secretariado que

\footnotetext{
A essência da profissão não se resume ao desempenho de tarefas rotineiras de escritório, mas pede também o domínio de determinados conhecimentos e habilidades, particularmente relativos a finanças, economia, marketing, administração, comércio exterior, contabilidade, tributação e relações humanas no trabalho (Medeiros \& Hernandes, 2012, p. 320).
}

Assim, vê-se no Secretário um profissional capaz de iniciar suas atividades em parceria com demais colegas, por já trazer em sua formação conhecimentos e habilidades que facilitam o desenvolvimento e gerência de uma cooperativa. Todavia, pela filosofia das cooperativas, não é exigido que o cooperado saiba como gerir uma cooperativa - por isso um dos princípios cooperativistas está ligado a educação. “As cooperativas proporcionam educação e treinamento aos sócios, dirigentes eleitos, administradores e funcionários, de modo a contribuir efetivamente para o seu desenvolvimento" (Crúzio, 2005, p, 33).

Cots (2007, p. 64) explica que "a cooperativa presta serviços aos seus cooperados para que estes prestem serviços ao mercado consumidor de forma mais vantajosa de que se atuassem isoladamente". Indica ainda que o potencial de crescimento destas associações é grande, pois de acordo com a Organização das Cooperativas Brasileiras, este tipo de cooperativa cresceu 22\% de 2004 para 2005.

Revista de Gestão e Secretariado - GeSec, São Paulo, v. 6, n. 1, p 99-125, jan./abr. 2015. 
Assim compreende-se que as expectativas mercadológicas para o cooperado são grandes, mas é preciso ponderar e analisar também os riscos na formação de uma Cooperativa bem como definir previamente o tipo de cooperativa que se está abrindo para avaliar sua inserção no mercado.

Diante do exposto, é inviável analisar as expectativas mercadológicas para uma cooperativa secretarial por tratar-se de um mercado ainda inexplorado pelos profissionais desta área. Assim, este artigo servirá como base para um próximo estudo.

Reportando ao profissional de secretariado, além do perfil de um cooperativado e formação em sua área, o secretário que optar atuar em cooperativa, tende a ser aquele que deseja abrir/gerir seu próprio negócio, e tem perfil empreendedor. Para Grion (2008, p. 30) a capacidade empreendedora do profissional de secretariado "é ideal não só no trabalho, mas também na vida pessoal e no ambiente social".

\section{4 ÁREAS DE ATUAÇÃo PROFISSIONAL: UMA ANÁLISE CONJUNTA}

De forma resumida, segue um quadro comparativo com as áreas de atuação do profissional de secretariado, a partir do exposto pelo referencial teórico e análises de resultados feitas ate então:

FORMAS DE ATUAÇÃO DO PROFISSIONAL DE SECRETARIADO EXECUTIVO

\begin{tabular}{|c|c|c|}
\hline & $\begin{array}{l}\text { REA DE } \\
\text { TUAÇÃ O }\end{array}$ & CARACTERÍSTICAS \\
\hline \multirow{4}{*}{ 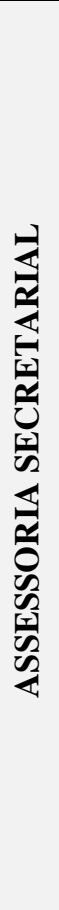 } & \multirow{2}{*}{$\begin{array}{c}\text { Direta } \\
\text { Home office }\end{array}$} & $\begin{array}{l}\text { - Habilidade de comunicação, no gerenciamento de informações e na } \\
\text { administração de conflitos internos e externos; } \\
\text { - conhecimento da organização como um todo, tendo visão holística dela; } \\
\text { - } \quad \text { planejamento e aplicação da liderança em equipes de trabalho; } \\
\text { - domínio e aplicação dos fundamentos da gestão organizacional, caracterizando- } \\
\text { se como gestor em seu setor e servindo de suporte gerencial os demais setores; } \\
\text { - ética e sensatez em seus pronunciamentos e ações; } \\
\text { - conhecimento da cultura organizacional, seus nichos mercadológicos e perfis } \\
\text { de clientes. }\end{array}$ \\
\hline & & $\begin{array}{l}\text { - } \quad \text { Perfil empreendedor, consciente de desafios e de riscos; } \\
\text { - gerenciamento de tempo para a melhor disponibilidade dos trabalhos; } \\
\text { inovação em seus serviços e práticas. }\end{array}$ \\
\hline & $\begin{array}{l}\text { Escritório } \\
\text { Virtual }\end{array}$ & $\begin{array}{l}\text { - } \quad \text { Perfil empreendedor; } \\
\text { - } \quad \text { habilidades em comunicação; } \\
\text { amplos conhecimentos em ferramentas tecnológicas. }\end{array}$ \\
\hline & Pool & $\begin{array}{l}\text { - } \quad \text { Regras bem definidas; } \\
\text { - } \quad \text { habirilidades para trabalhar em equipe; } \\
\text { - } \quad \text { desenvolvimento de confiança profissional; } \\
\text { maturidade profissional. }\end{array}$ \\
\hline
\end{tabular}

Revista de Gestão e Secretariado - GeSec, São Paulo, v. 6, n. 1, p 99-125, jan./abr. 2015. 


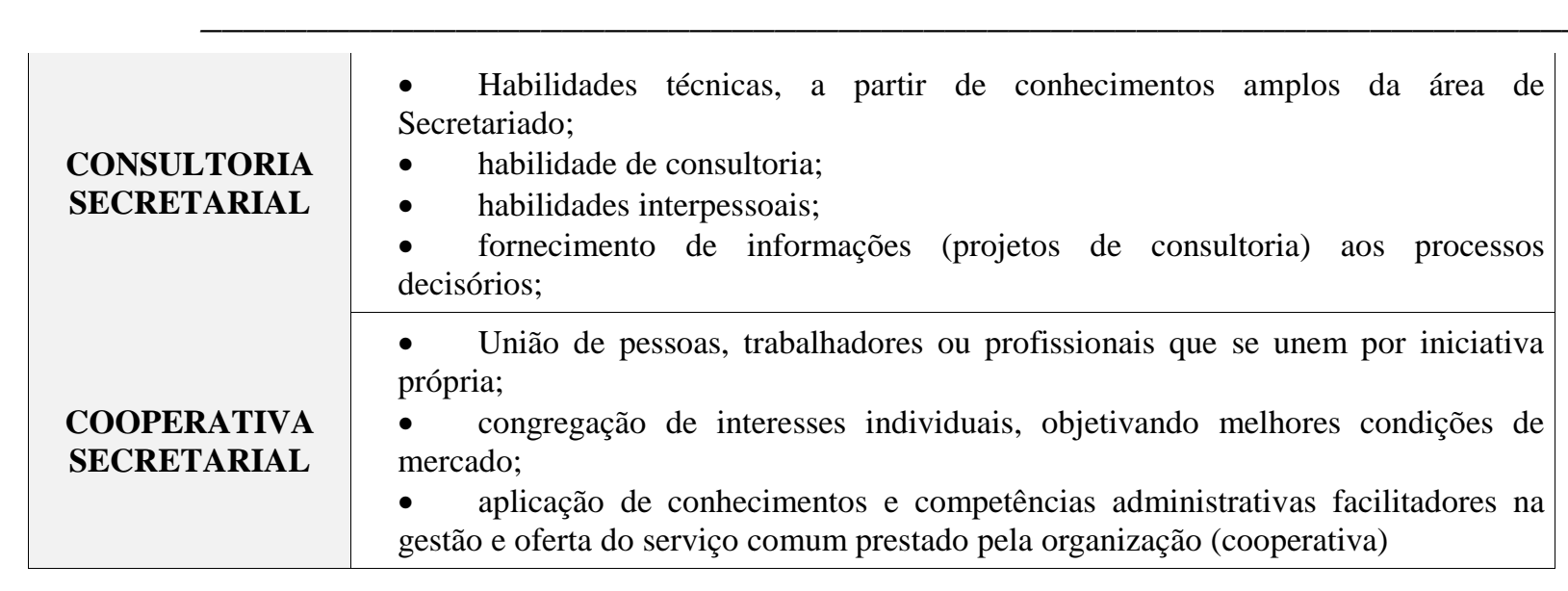

Quadro 1 - Formas de atuação do profissional de Secretariado Executivo Fonte: dados da pesquisa.

No quadro temos uma indicação do leque de atuação que se abre para o secretário. Observamos na atividade secretarial facilidade para ampliação de sua aplicabilidade, advinda da formação multidisciplinar que o secretário recebe.

\section{CONSIDERAÇÕES FINAIS}

O mercado secretarial está crescendo e as novas formas de atuação profissional começam a ser vistas e ocupadas por profissionais arrojados, com perfil empreendedor e que não temem romper os padrões de serviços empresa-secretário.

Diante da pesquisa foi possível concluir que ocupar estes novos estilos de atuação secretarial, como home office, escritórios virtuais e consultorias secretariais significam uma quebra de paradigmas da profissão, pois de modo geral, a concepção do leigo a respeito do trabalho do secretário esperando que ele esteja atrás de uma mesa, na empresa, a espera do gestor que lhe delegue tarefas, há muito tempo já foi ultrapassada. Essas novas áreas de atuação estão em expansão, mas ainda precisam ser pesquisadas individualmente em sua plenitude, verificando possibilidades e desafios para o secretário.

Assessorar deixa de ser uma função restrita em uma empresa e passa a ser uma atividade que pode ser desenvolvida de diversas formas, permitindo que o profissional de secretariado encontre novas oportunidades de inserção mercadológica. Além de encontrar oportunidades empreendedoras como atuar com escritórios virtuais e como consultor, o profissional de Secretariado encontra na assessoria novas formas de atuação como o pool secretarial e o home office.

Revista de Gestão e Secretariado - GeSec, São Paulo, v. 6, n. 1, p 99-125, jan./abr. 2015. 
Nota-se que, para atuar em home office, é necessário que haja uma relação sólida de confiança entre o profissional e seu gestor, mas que esta também configura uma forma de oferecer serviços personalizados a terceiros, caracterizando-se assim como uma nova possibilidade de fonte de renda. Já com relação ao escritório virtual, constatou-se que a prática deste serviço não é tão recente, e embora envolva muitas atividades ligadas ao desenvolvimento profissional do secretário executivo, este é um mercado pouco explorado.

Também foi possível perceber que entre essas formas de inserção do secretariado no mercado a consultoria secretarial tem crescido, foram encontradas algumas empresas que prestam esse tipo de serviço e dos serviços mais oferecidos pelos secretários consultores está a organização de arquivos, o gerenciamento de informações e rotinas, a organização de eventos e o assessoramento direto a profissionais.

Todas as atividades citadas anteriormente podem ser desenvolvidas por um ou mais profissionais, o que significa que o crescimento das empresas pode representar a contratação de mais profissionais - e o secretário que, então, atuava sozinho terá de se acostumar a dividir as tarefas. Este conceito de pool secretarial não é tão explorado pelos autores, uma vez que os que o fazem, mencionam que esta atuação facilita os conflitos entre os profissionais. Como este artigo é uma pesquisa introdutória, sugere-se a realização de um levantamento qualitativo e quantitativo para avaliar a aceitação profissional. Uma vez que o perfil do secretário indica que este está apto para trabalhar em equipe, os autores que abordam o sistema de trabalho em pool sugerem que o profissional tem dificuldade para adaptar-se a ele.

Com relação à área cooperativista, foi possível constatar que a inexistência de uma cooperativa secretarial é um tema ainda não explorado nas pesquisas secretariais, o que justifica a pesquisa em desenvolvimento neste trabalho. Uma vez que as cooperativas têm por objetivo a união de trabalhadores com objetivos comuns é possível elaborar uma hipótese a partir do questionamento da possibilidade de unir secretários executivos, que desenvolvem atividades individuais, como possíveis empreendedores, no fornecimento de serviços através de uma cooperativa secretarial.

Acredita-se que, com a criação de cooperativas em atividades secretariais, por meio da união de secretários trabalhando de forma autônoma, eles teriam maior visibilidade no mercado, sendo reforçados com os benefícios que a cooperativa pode oferecer aos seus cooperados. Dessa forma, este trabalho abordou tais formas de atuação, para posteriormente intensificar as pesquisas sobre o ramo de cooperativa, buscando explorar essa forma de atuação secretarial, vista aqui como 
inovadora no mercado.

\section{REFERÊNCIAS}

Administradores (2013). Cinco habilidades para se trabalhar em equipe. Recuperado em 5 de maio, 2014, de http://www.administradores.com.br/noticias/carreira/5-habilidades-fundamentaispara-se-trabalhar-em-equipe/77273/.

Albernaz, C. B. L. (2011). O secretário executivo como gatekeeper da informação. Tese de doutorado, Universidade de Brasília, Brasília, DF, Brasil.

Barros, C. M. P., Barbosa, M. F. S. \& Silva, J. S. da (2012). Fundamentação da Gestão Secretarial: um estudo bibliométrico. Revista Gestão e Secretariado - GeSec. 3(2), 106-126. Recuperado em 9 agosto, 2013, de http://www.revistagesec.org.br/ojs2.3.8/index.php/secretariado/article/view/114/pdf_14\#.UgzdW3-gyUV.

Barros, C. M. P.; Vasconcelos, L. S.; Silva, J. S. da; Brito, D. G. S. \& Silva Filho, M. C. da. (2012). A virtualidade no mundo do trabalho: um estudo sobre a atuação do secretário executivo virtual. Revista Expectativa, vol. XI n ${ }^{\circ}$ 11, jan.-dez./2012. Recuperado em 31 agosto, 2013, de http://erevista.unioeste.br/index.php/expectativa/issue/view/436/showToc.

Barros, A. J. da S. \& Lehfeld, N. A. de S. (2000). Fundamentos de metodologia científica: Um guia para a iniciação científica (2a ed.) São Paulo: Makron Books.

Bortolotto, M. F. P. \& Willers, E. M. (2005). Profissional de Secretariado Executivo: explanação das principais características que compõem o perfil. Revista Expectativa, 4(4), 45-56. Recuperado em 2 agosto, 2013, de http://erevista.unioeste.br/index.php/expectativa/issue/view/105/showToc.

Block, P. (2013). Consultoria infalível: Um guia prático, inspirador e estratégico. (3a ed.) São Paulo: M. Books.

Castelo, M. J. (2007). A formação acadêmica e profissional do secretário executivo. Trabalho de Conclusão de Curso, Universidade Estadual de Londrina, Londrina, PR, Brasil.

Cervo, A.R. \& Bervian, P. A. (2002). Metodologia científica (5a ed.) São Paulo: Prentice Hall.

Cots, M. E. R. (2007). Cooperativa de trabalho: Tratamento tributário e função social. Curitiba: Juruá.

Crúzio, H. de O. (2005). Como organizar e administrar uma cooperativa: Uma alternativa para o desemprego. (4a ed.) Rio de Janeiro: FGV.

Dale, E. \& Urwick, L. F. (1971). Organização e assessoria. São Paulo: Atlas.

Décia, A. C. M. (2005). A Information Literacy na formação do neo-secretário executivo: um estudo de caso na Graduação de Secretariado/UFBA. Dissertação de Mestrado, Universidade Federal da Bahia, Salvador, BA, Brasil.

Revista de Gestão e Secretariado - GeSec, São Paulo, v. 6, n. 1, p 99-125, jan./abr. 2015. 
Decreto 24.647, de 10 de julho de 1934. Revoga o decreto n. 22.239, de 19 de dezembro de 1932; Estabelece normas e princípios para a cooperação-profissional e para a cooperação social; faculta auxílios direitos e indiretos às cooperativas; e institui o Patrimônio dos Consórcios Patrimoniais Cooperativos. Recuperado 10 de maio, 2013, de http://www.planalto.gov.br/ccivil_03/decreto/1930-1949/D24647.htm.

Decreto-lei 59, de 21 de novembro de 1966. Define a política nacional de cooperativismo, cria o Conselho Nacional do Cooperativismo e dá outras providências. Recuperado em 10 de maio, 2013, de http://www.ocb.org.br/site/cooperativismo/arquivos/DecretoLei59_1966.pdf.

D’Elia, B., Amorim, M. \& Sita, M. (2013). Excelência no Secretariado: a importância da profissão nos processos decisórios. São Paulo: Ser Mais.

Dicionário Michaelis. (s.d) Dicionário online. Recuperado em 14 de junho, 2013, de http://michaelis.uol.com.br/moderno/ingles/index.php?lingua=ingles-portugues\&palavra=pool.

Durante, D. G. (2009). Gestão Secretarial: o desafio da visão holística. (Cap. 9, pp. 135-155). São Paulo: Viena.

Durante, D. G. \& Santos, M. E. M. (2010). A autonomia do secretário: Uma questão de postura e valorização profissional. Secretariado Executivo em Revista. (Vol.6) Recuperado em 16 junho, 2013, de http://www.upf.br/seer/index.php/ser/article/view/2097/1313.

Frigotto, G. (2002). Apresentação. In: ___ Educação e crise do trabalho: perspectiva de final de século. 6a ed. Petrópolis, RJ: Vozes. (Coleção estudos culturais em educação.)

Garcia, E. V. (2000). Noções fundamentais para a secretária. São Paulo: Summus.

Gil, A. C. (1999). Métodos e técnicas de pesquisa social (5a ed.). São Paulo: Atlas.

Gomes, A. R. (2007). Parceria entre o executivo e o profissional de secretariado. Mito ou realidade? Trabalho de Conclusão de Curso, Universidade Federal do Ceará, Fortaleza, CE, Brasil.

Grion, L. (2008). A nova secretária: Metacompetente, proativa, dinâmica. São Paulo: Madras.

Hopp, M. I. R. (1965). Conflitos entre assessores e administradores de linha. RAE - Revista de Administração de Empresas, 5(15), 105-114. Recuperado em 15 novembro, 2013, de http://rae.fgv.br/sites/rae.fgv.br/files/artigos/10.1590_S0034-75901965001500006.pdf.

Lei 5.764 de 16 de dezembro de 1971. Define a Política Nacional de Cooperativismo, institui o regime jurídico das sociedades cooperativas, e dá outras providências. Recuperado 20 de Junho, 2013, de http://www.planalto.gov.br/ccivil_03/leis/15764.htm.

Lei n. 7.377 de 30 de setembro de 1985. Dispõe sobre o exercício da profissão de secretário e dá outras providências. Recuperado 10 de maio, 2013 de http://www.planalto.gov.br/ccivil_03/leis/17377consol.htm.

Revista de Gestão e Secretariado - GeSec, São Paulo, v. 6, n. 1, p 99-125, jan./abr. 2015. 
Lei n. 9261 de 10 de janeiro de 1996. Altera a redação dos incisos I e II do art $2^{\circ}$, o caput do art. $3^{\circ}$, o inciso do VI do art. $4^{\circ}$ e o parágrafo único do art. $6^{\circ}$ da Lei $n^{\circ} 7.377$, de 30 de setembro de 1985. Recuperado em 10 de maio de 2013, de http://www.planalto.gov.br/ccivil_03/leis/L9261.htm.

Mazulo, R. \& Liendo, S. (2010) Secretária: rotina gerencial, habilidades comportamentais e plano de carreira. São Paulo: Senac.

Medeiros, J. B. \& Hernandes, S. (2012). Manual da Secretária. (12a ed.) São Paulo: Atlas.

Nasser, M.(2008). Socorro: Trabalho em pool!. A arte de secretariar. Recuperado em 14 de julho, 2013, de http://aartedesecretariar.blog.terra.com.br/2008/10/17/socorro-trabalho-em-pool/.

Nonato Jr., R. (2009). Epistemologia e teoria do conhecimento em secretariado executivo: a fundação das ciências da assessoria. Fortaleza: Expressão Gráfica.

Financeiro, Internauta. O Mercado de Consultoria no Brasil. (2012) IG Finance: negócios e consultoria. Recuperado em 16 de junho, 2013, de http://www.igfinance.com.br/noticias-fotos-evideos/o-mercado-de-consultoria-no-brasil/.

Pati, C. (2012a). As áreas que mais contratam em esquema de home office. Revista Exame. Recuperado em 14 de julho, 2013, de http://exame.abril.com.br/carreira/noticias/as-areas-quemais-contratam-em-esquema-de-home-office?page=2.

Pati, C. (2012b). Quatro perfis de profissionais que não combinam com o home office. Revista Exame. Recuperado em 29 de junho, 2013, de http://exame.abril.com.br/carreira/noticias/4perfis-de-profissionais-que-nao-combinam-com-home-office?page $=2$.

Pereira, S. R. G. \& Büllau, H. (2009). Escritórios virtuais: uma opção de prestação de serviços secretariais. In Durante, D.G. \& Fávero, A. A, (org.). Gestão Secretarial: formação e atuação profissional. Passo Fundo: Universidade de Passo Fundo.

Possas, M. L. (n.d.) Os conceitos de mercado relevante e de poder de mercado no âmbito da defesa da concorrência. Recuperado em 10 de junho, 2013, de: http://www.ie.ufrj.br/grc/pdfs/os_conceitos_de_mercado_relevante_e_de_poder_de_mercado.pdf

Roesch, S. M. A. (1999). Projetos de estágio e de pesquisa em administração: guia para estágio, trabalhos de conclusão, dissertações e estudos de caso (2a ed.). São Paulo: Atlas.

Rodrigues, A. G. (2002). O papel do consultor administrativo externo no fortalecimento do negócio. Belém, recuperado em 4 de julho, 20130, de http://www.planoauditoria.com.br/site/download/110908_monografia_adna.pdf.

Sabino, R. F. (2006). A profissão de secretário executivo no Brasil: políticas para formação e emprego. Dissertação de Mestrado, Universidade São Marcos, Tatuapé, SP, Brasil.

Sabino, R. F. \& Marchelli, P. S. (2009). O debate teórico-metodológico no campo do secretariado: pluralismos e singularidades. Cad. Ebape. Br, 7(4), 607-621. Recuperado em 14 outubro, 2011,

Revista de Gestão e Secretariado - GeSec, São Paulo, v. 6, n. 1, p 99-125, jan./abr. 2015. 
de

http://www.scielo.br/scielo.php?script=sci_arttext\&pid=S167939512009000400006\&lng=pt\&nrm=iso.

Santos, C. V. dos \& Caimi, F. E.(2009). Secretário executivo: formação, atribuições e desafios profissionais. In: Durante, D. G., Fávero, A. A. (org.). Gestão secretarial: formação e atuação profissional. Passo Fundo, RS: Ed. Universidade do Passo Fundo.

Schirigatti, E. L. \& Kasprzak, L. F. F. (2007). Home Office: origem, conceito e interferências sobre o significado social do novo modelo de trabalho flexível. Revista Científica de Administração e Sistema de Informação. (Vol. 8, n. 8) Recuperado em 14 de julho, 2013, de http://www.faculdadeexpoente.edu.br/upload/noticiasarquivos/1208992587.pdf..

Souza, I. F. \& Silva Filho, G. A. (2010). Mercado de trabalho para o profissional de Secretariado Executivo no município de Cuiabá/MT. Anais do Simpósio de Excelência de Gestão e Tecnologia. Resende, RJ, Brasil, 7.

Tortorette, M. (2010). Trabalho em equipe: desenvolva esta habilidade. Catho. Recuperado em 30 de junho, 2013, de http://www.catho.com.br/carreira-sucesso/sem-categoria/trabalho-em-equipedesenvolva-esta-habilidade.

Vergara, S. C. (2007). Projetos e relatórios de pesquisa em administração (9a ed.). São Paulo: Atlas.

Revista de Gestão e Secretariado - GeSec, São Paulo, v. 6, n. 1, p 99-125, jan./abr. 2015. 